\title{
Targeting the Autonomic Nervous System Balance in Patients with Chronic Low Back Pain Using Transcranial Alternating Current Stimulation: A Randomized, Crossover, Double-Blind, Placebo-Controlled Pilot Study
}

This article was published in the following Dove Press journal: Journal of Pain Research

\begin{abstract}
Julianna $\mathrm{H}$ Prim ${ }^{1-3, *}$
Sangtae Ahn ${ }^{1,2, *}$

Maria I Davila'

Morgan L Alexander ${ }^{1,2}$

Karen L McCulloch ${ }^{3,4, *}$

Flavio Fröhlich (iD) $1,2,5-8, *$

'Department of Psychiatry, University of North Carolina at Chapel Hill, Chapel Hill, NC 27599, USA; ${ }^{2}$ Carolina Center for Neurostimulation, University of North Carolina at Chapel Hill, Chapel Hill, NC 27599, USA; ${ }^{3}$ Department of Allied Health Sciences, Human Movement Science Curriculum, University of North Carolina at Chapel Hill, Chapel Hill, NC 27599, USA;

${ }^{4}$ Division of Physical Therapy, University of North Carolina at Chapel Hill, Chapel Hill, NC 27599, USA; ${ }^{5}$ Department of Neurology, University of North Carolina at Chapel Hill, Chapel Hill, NC 27599, USA; ${ }^{6}$ Department of Biomedical Engineering, University of North Carolina at Chapel Hill, Chapel Hill, NC 27599, USA; ${ }^{7}$ Department of Cell Biology and Physiology, University of North Carolina at Chapel Hill, Chapel Hill, NC 27599, USA; ${ }^{8}$ Neuroscience Center, University of North Carolina at Chapel Hill, Chapel Hill, NC 27599, USA
\end{abstract}

*These authors contributed equally to this work

Correspondence: Flavio Fröhlich University of North Carolina at Chapel Hill II 6 Manning Dr, Mary Ellen Jones Building 6018, Chapel Hill, NC 27599, USA

$\mathrm{Tel}+$ I 9199664584

Email flavio_frohlich@med.unc.edu
Background: Chronic low back pain (CLBP) is characterized by an alteration in pain processing by the central nervous system that may affect autonomic nervous system (ANS) balance. Heart rate variability (HRV) reflects the balance of parasympathetic and sympathetic ANS activation. In particular, respiratory sinus arrhythmia (RSA) solely reflects parasympathetic input and is reduced in CLBP patients. Yet, it remains unknown if non-invasive brain stimulation can alter ANS balance in CLBP patients.

Objective: To evaluate if non-invasive brain stimulation modulates the ANS, we analyzed HRV metrics collected in a previously published study of transcranial alternating current stimulation (tACS) for the modulation of CLBP through enhancing alpha oscillations. We hypothesized that tACS would increase RSA.

Methods: A randomized, crossover, double-blind, sham-controlled pilot study was conducted to investigate the effects of $10 \mathrm{~Hz}$-tACS on metrics of ANS balance calculated from electrocardiogram (ECG). ECG data were collected for 2 mins before and after 40 mins of $10 \mathrm{~Hz}$-tACS or sham stimulation.

Results: There were no significant changes in RSA or other frequency-domain HRV components from $10 \mathrm{~Hz}-\mathrm{tACS}$. However, exploratory time-domain HRV analyses revealed a significant increase in the standard deviation of normal intervals between R-peaks (SDNN), a measure of ANS balance, for $10 \mathrm{~Hz}$-tACS relative to sham.

Conclusion: Although tACS did not significantly increase RSA, we found in an exploratory analysis that tACS modulated an integrated HRV measure of both ANS branches. These findings support the further study of how the ANS and alpha oscillations interact and are modulated by tACS.

ClinicalTrials.gov: Transcranial Alternating Current Stimulation in Back Pain - Pilot Study, NCT03243084

Keywords: low back pain, autonomic nervous system, heart rate variability, transcranial alternating current stimulation

\section{Introduction}

Chronic pain is a severe, disabling condition that affects $25-30 \%$ of the population in the United States ${ }^{1}$ and treatment options are limited. ${ }^{2}$ While opioid therapy has shown short-term efficacy in decreasing pain, few studies have investigated its long-term 
effectiveness $^{3}$ and systematic reviews identify multiple severe risks of long-term use including: misuse, abuse/ dependence, overdose, and death. ${ }^{3,4}$ Chronic low back pain (CLBP) is the second most prevalent cause of disability in adults in the US. ${ }^{5}$ The poor rates of recovery $(58 \%$ at 1 month) and high rates of recurrence ( $73 \%$ in 12 months) contribute to high social and economic costs. ${ }^{6}$

CLBP often persists without clear peripheral pathology (peripheral injury may trigger but does not sustain CLBP) and the mechanism of pain development is not fully understood. ${ }^{7}$ CLBP stems from dynamic interactions between sensory and contextual (i.e., cognitive, emotional, and motivational) processes in the brain that are mediated by feed-forward and feedback processes. ${ }^{8}$ In CLBP, the relationship between nociception and pain is often weak or lost indicating abnormal integration, ${ }^{8}$ which points to an alteration in pain processing by the central nervous system. ${ }^{9,10}$ Noninvasive brain stimulation has the potential to help renormalize network pathologies associated with chronic pain. ${ }^{8,11,12}$ Previous studies, which investigated non-invasive brain stimulation interventions in chronic pain, have shown promising, but varied results. ${ }^{12}$ Most of these studies have focused on transcranial direct current stimulation and transcranial magnetic stimulation, yet transcranial alternating current stimulation can modulate impaired alpha oscillations in patients with chronic pain. ${ }^{13}$

Recent neurobiological investigations support the crucial role of the brain within chronic pain development by showing substantial structural, physiological, and metabolic changes ${ }^{8}$ including autonomic nervous system (ANS) balance. ${ }^{14}$ The ANS controls a range of vital involuntary physiological functions, such as regulating blood pressure, temperature, and heart rate at rest and in response to stressors. ${ }^{15}$ Regulatory ANS function can be quantitatively assessed by the analysis of the heart rate variability (HRV), which is the variation in time between successive heartbeats. HRV is composed of input from the excitatory sympathetic and inhibitory parasympathetic nervous system as well as baroreceptors and vagal tone. When HRV is deconstructed through signal processing, it is possible to quantify rhythmic components that reflect specific pathways of the ANS neural regulation. The most salient components are a respiratory oscillation known as respiratory sinus arrhythmia $(\mathrm{RSA})^{16}$ and low-frequency (LF) components assumed to be related to blood pressure regulation via the baroreceptors and peripheral vasomotor activity. $^{17,18}$
Pain signal regulation is a normal part of the defensive response mediated by the nervous system. The body reacts to illness by activating and sensitizing afferent nociceptive neurons. ${ }^{19}$ In the case of chronic pain, this process may trigger hyperarousal of the sympathetic nervous system. ${ }^{20}$ Based on the Polyvagal theory, ${ }^{21,22}$ an evolutionary neurophysiological model of the autonomic response to safety and threat, chronic maintenance of threat responses can lead to a compromised functional state. ${ }^{23}$ These chronic systemic functional problems are reflected in the regulation of the heart by the most rapidly responsive component of the nervous system, the ventral vagal complex, as measured by RSA. ${ }^{22}$ Previous studies have sought to increase RSA using biofeedback interventions, and HRV components have been used to measure the efficacy of chronic pain therapies. ${ }^{24-27}$ Yet, little is known if modulating neural oscillations by non-invasive brain stimulation can influence ANS balance in patients with CLBP.

We performed a randomized, crossover, double-blind, sham-controlled clinical trial to investigate the effect of transcranial alternating current stimulation (tACS), which is a form of non-invasive brain stimulation that applies weak sine-wave electrical current to the scalp and can modulate oscillatory brain network activity, ${ }^{28-30}$ in patients with CLPB. In a separate publication on this study, we reported that tACS enhanced impaired alpha oscillations and that pain relief correlated with the stimulation-induced increase in alpha oscillations in patients with CLBP. ${ }^{13}$ We hypothesized that tACS would increase RSA, and therefore reduced CLBP, based on previous findings that patients with CLBP show pathologically reduced RSA compared to healthy controls. ${ }^{31-36}$ Exploratory analyses will be performed for other HRV components in both time and frequency domains. However, since the direct link from these metrics to autonomic nervous system branches is unclear, no a priori hypotheses regarding these analyses were made.

\section{Methods}

\section{Participants}

The inclusion criteria were as follows: 1) age between 18 and $65 ; 2$ ) self-reported clinical diagnosis of chronic low back pain (lumbosacral region); 3) pain for at least 6 months; 4) an average daily pain rating $\geq 4$ as measured by a $0-10$ numeric rating scale (NRS); 5) no history of neurologic or psychiatric conditions and no current unstable medical conditions; 6) no contraindications to 
tACS such as metal implants in the brain or epilepsy; and 7) no current pregnancy. The study was approved by the Biomedical Institutional Review Board (IRB) of University of North Carolina at Chapel Hill and registered on clinicaltrials.gov (NCT03243084) and was conducted in accordance with the Declaration of Helsinki. All participants signed an IRB approved informed consent form. Participants were recruited from local pain and physical therapy clinics, as well as the University listserv email and a recruitment website (jointheconquest.org). Participation consisted of two sessions and two follow-up emails after a telephone screening was used to determine initial eligibility. Participants also met criteria for low depression (total score <17) and suicide risk as defined by the Hamilton Depression Rating Scale $^{37}$ (suicide question score $\leq 2)$.

\section{Study Design}

We conducted a randomized, crossover, double-blind, sham-controlled trial. Participants received both $10 \mathrm{~Hz}-$ tACS and active sham stimulation in a randomized and counter-balanced order with a separation of at least 1 week between sessions. Each stimulation session was preceded and followed by ECG and clinical pain assessments.

\section{Brain Stimulation}

We applied $10 \mathrm{~Hz}$-tACS via three silicone-carbon electrodes on the scalp with Ten20 conductive paste (BioMedical Instruments, Clinton Township, MI) and the XCISTE 100 stimulator (Pulvinar Neuro, Chapel Hill, NC). The two stimulation electrodes $(5 \times 5 \mathrm{~cm})$ were placed at F3 and F4 according to the 10-20 international coordinate system (Figure 1). Stimulation montage and modeling of electric field distribution were calculated by the tES LAB 1.0 software (Neurophet Inc., Seoul, South Korea). The return electrode $(5 \times 7 \mathrm{~cm})$ was placed slightly below Pz. The two stimulation electrodes each delivered an inphase sinusoidal waveform with $1 \mathrm{~mA}$ zero-to-peak amplitude. Stimulation ramped up and down for $10 \mathrm{~s}$. For active $10 \mathrm{~Hz}-\mathrm{tACS}$, the stimulation lasted for $40 \mathrm{mins}$. Sham stimulation was identical to active, except that stimulation only lasted for $1 \mathrm{~min}$. All participants completed the $10 \mathrm{~Hz}-$ tACS and sham stimulation for 40 mins on a different day. There was a required gap of at least 7 days between the two sessions to reduce carry-over effects (14.4 days \pm 6.5 ). Five-digit codes were used to ensure that study coordinators were blind to the stimulation condition. During stimulation, all participants were seated comfortably and watched Reefscapes (Undersea Productions, Queensland, Australia), which displays tropical fish in underwater scenes, to minimize the phosphenes induced by stimulation. Participants were asked to stay relaxed, watch the video, and keep their eyes open.

\section{Clinical Assessments}

Participants completed a battery of baseline surveys including demographics, handedness, State-Trait Anxiety Inventory (STAI) (Trait-version), ${ }^{38}$ Behavioral Inhibition and Activation Scales (BIS/BAS), ${ }^{39,40}$ and pre-treatment opinion on the likelihood of pain improvement (0-10 numeric rating scale). Other self-report baseline measures included the Pain Catastrophizing Scale (PCS), ${ }^{41,42}$ Depression Anxiety Stress Scales (DASS-21), ${ }^{43}$ UCLA Activity Score, ${ }^{44}$ and Pain Self-efficacy Questionnaire (PSEQ), ${ }^{45}$ which assessed pain experience, depression levels, physical activity limitations, and confidence in daily activities, respectively.

Pain severity and disability were assessed both prior to and after receiving stimulation. The pain scale utilized was an 11 point NRS (0-10) that includes word and facial descriptions and is part of the previously validated Defense and Veterans Pain Rating Scale (DVPRS). ${ }^{46}$ The DVPRS was a repeated measure completed at the beginning and end of both sessions and a two-day follow-up email after each session. It also includes domain-specific questions about pain interference in activity, mood, sleep, and stress in the last 24 hrs (answered at session beginning and follow-up only). Disability was measured by the Oswestry Disability Index (ODI), ${ }^{4,48}$ a back-painspecific assessment measuring perception of disability. The ODI was another repeated measure that was completed at the beginning of each session and at follow-up. A pressure pain threshold (PPT) test using the Wagner FDX Algometer (Wagner Instruments FDX-25, Greenwich, Connecticut) was assessed to help quantify and document levels of pain sensitivity via pain tolerance measurement. PPT was assessed before and after stimulation at the right brachioradialis and right sacroiliac joint. ${ }^{49}$ The participant was instructed to inform the assessor when they first perceived a sensation of pain. The amount of pressure in pounds (lb) that constituted the pain sensation was recorded for PPT. This process was repeated three times at each site and the average of these measures was used in the data analysis. The test-retest reliability of PPT measurements has been established in previous studies. $^{50,51}$ 


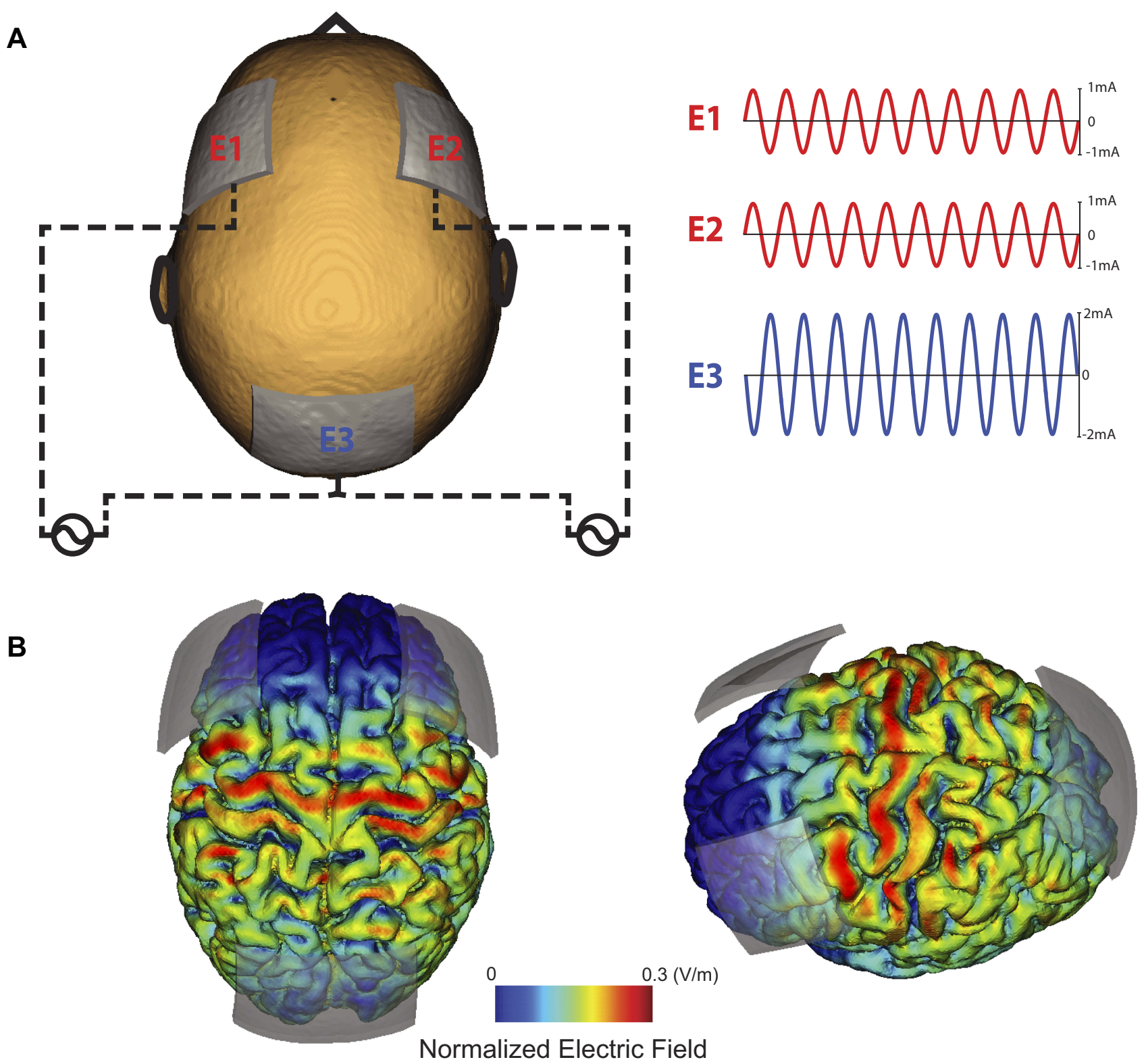

Figure I Stimulation montage and electric field distribution. (A) Electrode EI and E2 deliver ImA (zero-to-peak) in-phase sine-wave. Electrode E3 is used as a return electrode. (B) Normalized electric field distribution on the cortex (left: top-view, right: left-view).

\section{ECG Data Collection and Analysis}

ECG data were collected with the Physio16 input box (Geodesic EEG System, EGI Inc., Eugene, OR) at a sampling rate of $1 \mathrm{kHz}$. HRV components were extracted from ECG data ${ }^{17,52}$ to evaluate changes in neural regulation of the ANS before and after intervention. Prior to the baseline HRV recording, participants had been seated resting while they completed clinical assessments and stimulation electrodes were applied, allowing for heart rate to normalize after arrival. During HRV recordings, participants were seated and instructed to relax while looking at a crosshair on a computer screen. We placed two disposable snap electrodes below the right clavicle and left inferior costal margin. Inter-beat intervals (IBI), which is the time between consecutive heartbeats expressed in milliseconds, were derived from detected $\mathrm{R}$ peaks in ECG data. The R peaks were extracted using the Cardio Peak-Valley Detector $(\mathrm{CPVD})^{53}$ and the IBI event series were obtained. The unedited IBI file was visually inspected and edited offline with CardioEdit software (developed in the Porges laboratory and implemented by researchers trained in the Porges laboratory). Editing consisted of integer arithmetic (i.e., dividing intervals between heart beats when detections of R-wave from the ECG were missed or adding intervals 
when spurious invalid detections occurred). The resulting normal RR intervals were used in analysis when abnormal beats like ectopic beats (heartbeats that originate outside the right atrium's sinoatrial node) were removed. ${ }^{54} \mathrm{HRV}$ time and frequency components were calculated with MATLAB and CardioBatch software (Brain-Body Center, University of Illinois at Chicago), respectively. For HRV time components, the average of normal RR intervals (mean RR), the standard deviation of normal intervals between R-peaks (SDNN), and the root-mean-square differences of successive RR intervals (RMSSD) were calculated using custombuilt scripts in MATLAB. For HRV frequency components, RSA was calculated using CardioBatch software, which implements the Porges-Bohrer metric. ${ }^{52}$ This metric is neither moderated by respiration, nor influenced by nonstationarity, and reliably generates stronger effect sizes than other commonly used metrics of RSA (steps are described in depth in $^{55}$ and validated $\mathrm{in}^{52}$ ). To derive the other HRV frequency components (Low Frequency, and Low Frequency/High Frequency), the IBI event series was resampled at $2 \mathrm{~Hz}$ to generate an equally spaced interval time series. RSA and LF were calculated based on the Porges-Bohrer method; ${ }^{55,56}$ RSA uses a third-order, 21point moving polynomial filter (MPF) applied to the $2 \mathrm{~Hz}$ IBI time series to remove low-frequency oscillations and slow trend. The residual detrended output of the MPF was filtered with a Kaiser FIR windowed filter with cut-off frequencies that removes variance not related to spontaneous breathing in adults $(0.12$ to $0.40 \mathrm{~Hz})$. The filtered detrended output was divided into sequential 30-s epochs and the variance within each epoch was transformed by a natural $\operatorname{logarithm}(\ln (\mathrm{ms} 2))$; the mean of these epoch values was used as the estimate of RSA for the specific segment. LF uses a third-order, 51-point moving polynomial filter (MPF) applied to the $2 \mathrm{~Hz}$ IBI trend to remove extremely low-frequency oscillations and slow trend. The residual detrended output of the MPF was filtered with a Kaiser FIR windowed filter with cut-off frequencies $(0.04$ to $0.10 \mathrm{~Hz})$. The filtered detrended output was divided into 30-s epochs and the variance within each epoch was transformed with a natural logarithm $(\ln (\mathrm{ms} 2))$; the mean of the epoch values was used as an estimate of LF for the segment. ${ }^{57}$ These variables included: 1) respiratory sinus arrhythmia (i.e., RSA or high frequency HRV defined by the frequencies of spontaneous breathing $(0.12-0.4 \mathrm{~Hz}), 2)$ low-frequency HRV (i.e., occurring within the frequencies of spontaneous vasomotor and blood pressure oscillations; $0.06-0.10 \mathrm{~Hz}$ ), and 3) ratio of LF and HF (LF/HF).

\section{Statistical Analyses}

All statistical analyses were performed using custom-built scripts in R ( $\mathrm{R}$ Foundation for Statistical Computing, Vienna, Austria). All analyses were run on the difference of data before and after stimulation (post-pre) after taking the natural logarithm (within Porges-Bohrer method). A two-way repeated-measures ANOVA was run with a factor for the stimulation condition $(10 \mathrm{~Hz}-\mathrm{tACS}$ vs sham), session (first vs second), and interaction between the two (sequence of $10 \mathrm{~Hz}$-tACS-sham or sham-10HztACS) for RSA. The session factor was included to control for non-specific effects that the session order might induce. The exploratory analysis of other HRV components (LF, LF/HF, Mean RR, SDNN, RMSSD) included the same two-way repeated-measures ANOVA. Alpha was set at 0.05. Exploratory Pearson correlation analyses were run to investigate the relationship between pain (severity DVPRS, acute processing - PPT) and RSA at baseline and change (post-pre) within the session.

\section{Results Demographics}

The consort diagram is presented in Figure $2 .{ }^{13}$ Twenty of the twenty-one participants recruited completed the study. Eighty percent of participants reported CLBP with a duration of greater than two years (Table 1, Supplementary Table 1). The most common previous treatment reported included the use of NSAIDs, physical or aquatic therapy, alternative treatments, and low impact exercise such as yoga. All participants reported trying at least two previous treatment options. Full demographics are reported in Table 1.

\section{RSA and HRV Components}

The HRV frequency-domain components followed normal distribution as defined by the Wilks-Sharpiro test $(\mathrm{p}>0.05)$. RSA was analyzed using a two-way repeated-measured ANOVA of condition (10 Hz-tACS and sham) and session (first visit and second visit). In this analysis, the interaction of condition and session was considered to represent a sequence effect if present. For RSA, we found no significant main effect for condition $\left(\mathrm{F}_{1,35}=1.01, \mathrm{p}=0.32\right)$, session $\left(F_{1,35}=0.33, p=0.57\right)$, or sequence $\left(F_{1,35}=0.66\right.$, $\mathrm{p}=0.42$ ) (Figure 3A, left panel). We ran the same twoway repeated-measures ANOVA for $\mathrm{LF}$ and $\mathrm{LF} / \mathrm{HF}$. We found no significant effects of condition $\left(\mathrm{F}_{1,35}=1.56\right.$, $\mathrm{p}=0.22)$, session $\left(\mathrm{F}_{1,35}=2.91, \mathrm{p}=0.10\right)$, or sequence $\left(\mathrm{F}_{1,35}=\right.$ $1.44, \mathrm{p}=0.24)$ for LF nor did we find significant effects of 


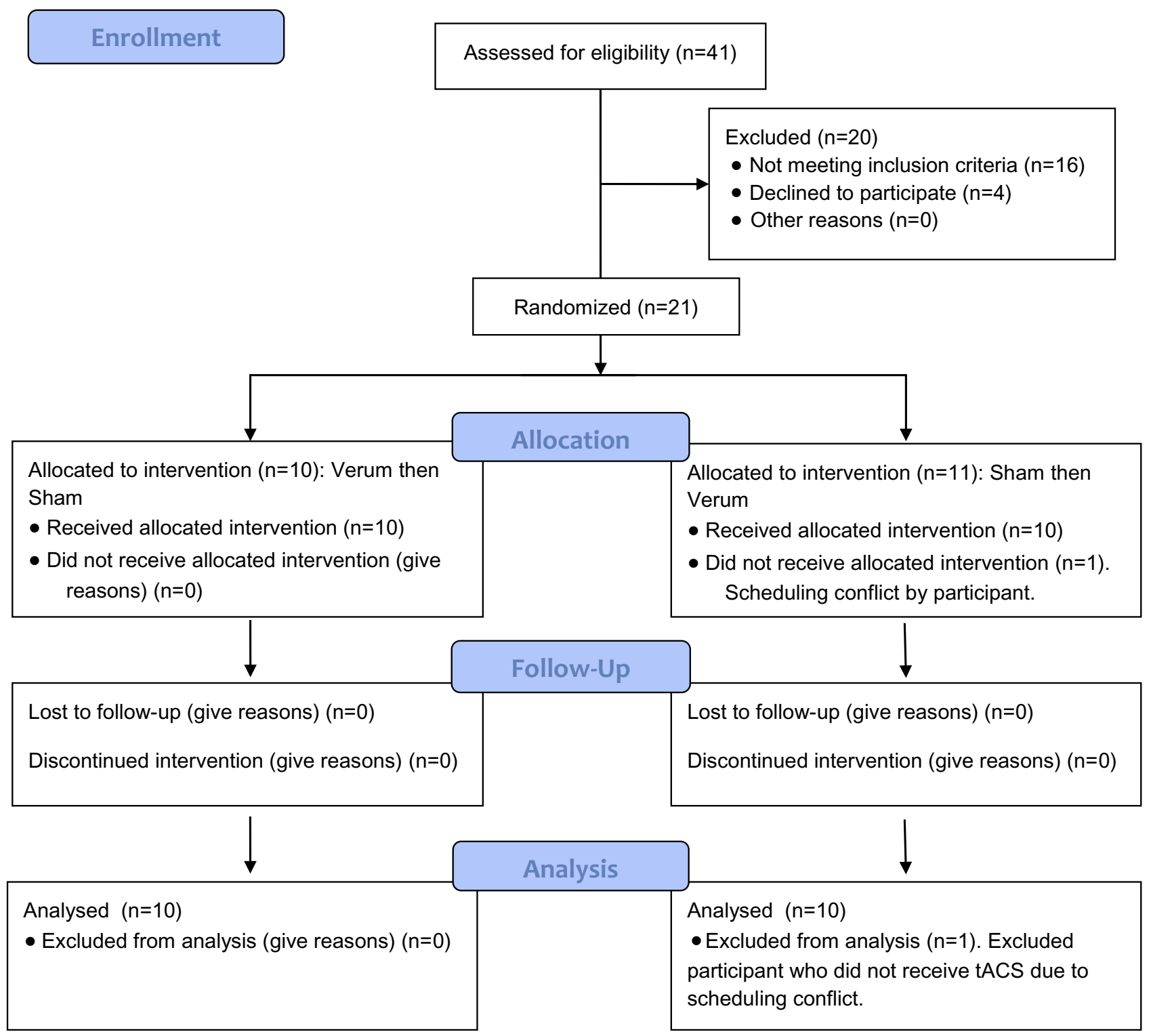

Figure 2 Consort (2010) flow diagram.

condition $\quad\left(\mathrm{F}_{1,35}=0.14, \mathrm{p}=0.72\right)$, session $\quad\left(\mathrm{F}_{1,35}=2.63\right.$, $\mathrm{p}=0.11)$, or sequence $\left(\mathrm{F}_{1,35}=0.84, \mathrm{p}=0.37\right)$ for $\mathrm{LF} / \mathrm{HF}$ (Figure 3A, middle and right panels). In the time-domain analyses, we found a trend-level main effect of condition for mean $R R\left(F_{1,35}=2.92, p=0.096\right)$ but not session $\left(F_{1,35}\right.$ $=0.012, \quad \mathrm{p}=0.91) \quad$ or $\quad$ sequence $\quad\left(\mathrm{F}_{1,35}=0.11 \quad \mathrm{p}=0.74\right.$; Figure 3B, left panel). For the standard deviation of normal intervals of R-peaks (SDNN), we found a significant main effect of condition $\left(\mathrm{F}_{1,35}=5.34, \mathrm{p}=0.027\right)$, but not session $\left(\mathrm{F}_{1,35}=0.00, \mathrm{p}=0.999\right)$ or sequence $\left(\mathrm{F}_{1,35}=0.29\right.$, $\mathrm{p}=0.59$; Figure $3 \mathrm{~B}$, middle panel). Post-hoc paired $t$-tests yielded a significant SDNN increase in the $10 \mathrm{~Hz}$-tACS condition $\left(\mathrm{t}_{19}=2.07, \mathrm{p}=0.05\right)$. We found no significant difference in RMSSD for condition $\left(\mathrm{F}_{1,35}=2.59, \mathrm{p}=0.12\right)$, session $\left(\mathrm{F}_{1,35}=0.16, \mathrm{p}=0.69\right)$, or sequence $\left(\mathrm{F}_{1,35}=0.02\right.$, $\mathrm{p}=0.88$; Figure $3 \mathrm{~B}$, right panel). These findings suggest that tACS modulated total HRV (both sympathetic and parasympathetic input) in patients with CLBP. Values for the pain and HRV metrics are presented in Table 2.

\section{HRV Correlation to Pain}

To investigate the presence of a relationship between baseline RSA and pain level, we calculated the Pearson correlation for the pre-stimulation time point (Table 3A). Neither RSA nor SDNN measures correlated with baseline pain level, ODI, or PPT (Table 3A). We also investigated 
Table I Demographic Information

\begin{tabular}{|c|c|}
\hline Demographics & $\begin{array}{l}\text { Participants } \\
(n=20)\end{array}$ \\
\hline Age & $43.00(13.37)$ \\
\hline \multicolumn{2}{|l|}{ Sex, N (\%) } \\
\hline Male & $8(40 \%)$ \\
\hline Female & $12(60 \%)$ \\
\hline \multicolumn{2}{|l|}{ Race, N(\%) } \\
\hline Caucasian & $18(90 \%)$ \\
\hline African American & $2(10 \%)$ \\
\hline \multicolumn{2}{|l|}{ Ethnicity, N(\%) } \\
\hline Hispanic/Latino & I (5\%) \\
\hline Non-Hispanic/Latino & $19(95 \%)$ \\
\hline BMI & $25.94(4.46)$ \\
\hline \multicolumn{2}{|l|}{ Handedness } \\
\hline Right & $18(90 \%)$ \\
\hline Left & $2(10 \%)$ \\
\hline Time in Pain (years) & $7.1(6.0)$ \\
\hline $0-2$ yrs, $N(\%)$ & $4(20 \%)$ \\
\hline $2-5$ yrs, $N(\%)$ & $8(40 \%)$ \\
\hline $5+$ yrs, $N(\%)$ & $8(40 \%)$ \\
\hline \multicolumn{2}{|l|}{ Previous Treatment, N (\%) } \\
\hline Physical or Aquatic therapy & $13(65 \%)$ \\
\hline Opioids & $4(20 \%)$ \\
\hline Over the counter medications (e.g., NSAID) & $18(90 \%)$ \\
\hline $\begin{array}{l}\text { Alternative Treatments (e.g., chiropractor, } \\
\text { acupuncture) }\end{array}$ & $13(65 \%)$ \\
\hline Surgery & $3(15 \%)$ \\
\hline Counseling, Cognitive Behavioral Therapy & I (5\%) \\
\hline Social support (e.g., chronic pain social group) & I (5\%) \\
\hline Low-impact exercise (e.g., yoga, pilates) & $13(65 \%)$ \\
\hline Mindfulness Intervention & $3(15 \%)$ \\
\hline Other & $5(25 \%)$ \\
\hline \multicolumn{2}{|l|}{ Self-Report Assessments (Baseline) } \\
\hline $\begin{array}{l}\text { Pre-treatment Opinion on likelihood of pain } \\
\text { improvement (0-10 NRS, not likely at all to very } \\
\text { likely) }\end{array}$ & $3.75(1.62)$ \\
\hline Defense and Veterans Pain Rating Scale & $4.4(1.05)$ \\
\hline \multicolumn{2}{|l|}{ Pain Interference with: } \\
\hline Activity & $4.8(1.67)$ \\
\hline Sleep & $5.00(2.62)$ \\
\hline Mood & $4.10(1.68)$ \\
\hline Stress & $4.35(2.23)$ \\
\hline Oswestry Disability Index & $28.52(I I .5 I)$ \\
\hline UCLA Activity score & $5.9(2.29)$ \\
\hline Low, N (\%) & $4(20 \%)$ \\
\hline Medium, N (\%) & $10(50 \%)$ \\
\hline
\end{tabular}

(Continued)
Table I (Continued).

\begin{tabular}{|c|c|}
\hline Demographics & $\begin{array}{l}\text { Participants } \\
(n=20)\end{array}$ \\
\hline High, N (\%) & $6(39 \%)$ \\
\hline $\begin{array}{l}\text { Pain Catastrophizing Scale (PCS) Total } \\
\text { Rumination } \\
\text { Magnification } \\
\text { Helplessness }\end{array}$ & $\begin{array}{l}15.05(9.78) \\
5.8(4.76) \\
3.2(2.38) \\
6.05(3.65)\end{array}$ \\
\hline Pain Self Efficacy Questionnaire (PSEQ) Total & $37.6(12.14)$ \\
\hline $\begin{array}{l}\text { BIS/BAS Scale } \\
\text { BAS Drive } \\
\text { BAS Fun Seeking } \\
\text { BAS Reward Responsiveness } \\
\text { BIS }\end{array}$ & $\begin{array}{l}10.3(2.36) \\
11.9(1.97) \\
17.3(1.95) \\
20.3(4.12)\end{array}$ \\
\hline $\begin{array}{l}\text { State-Trait Anxiety Inventory (STAI-Trait) } \\
\text { Depression and Anxiety Subscale (DASS-2I) }\end{array}$ & $\begin{array}{l}43.25(10.36) \\
15.55(13.34)\end{array}$ \\
\hline \multicolumn{2}{|l|}{ Clinical Assessments (Baseline) } \\
\hline $\begin{array}{l}\text { HAMD-I7 } \\
\text { Pressure Pain Threshold (PPT) } \\
\text { Brachioradialis (lb) } \\
\text { Sacroiliac Joint (lb) }\end{array}$ & $\begin{array}{l}8.9(3.46) \\
4.8(2.37) \\
8.99(3.95)\end{array}$ \\
\hline \multicolumn{2}{|l|}{ HRV Components (Baseline) } \\
\hline $\begin{array}{l}\text { Respiratory Sinus Arrhythmia (RSA) or High } \\
\text { Frequency (HF) } \\
\text { Low Frequency (LF) } \\
\text { LF/HF } \\
\text { Mean RR } \\
\text { Standard Deviation of RR Intervals (SDNN) } \\
\text { Root Mean Square of Successive Differences } \\
\text { (RMSSD) }\end{array}$ & $\begin{array}{l}4.84(1.37) \\
0.89(0.21) \\
899.99(149.04) \\
46.56(27.63) \\
41.02(36.58)\end{array}$ \\
\hline
\end{tabular}

Note: Baseline refers to the pre-stimulation measures of session 1.

Abbreviations: BMI, Body Mass Index; BIS/BAS, Behavioral Inhibition System/ Behavioral Activation System Scale; HamD-17, Hamilton Depression Rating Scale; HRV, Heart Rate Variability; LF/HF, ration of Low Frequency to high frequency; Mean RR, Mean time between RR (all R peaks) intervals.

the change in RSA and SDDN with pain, ODI, and PPT change. We found neither RSA nor SDNN correlated with pain, ODI, and PPT change (Table 3B).

\section{Responders}

Responders in this study are defined by participants who had a decrease of two points or more on the DVPRS (11 point NRS) after stimulation, which indicates the minimal clinically important difference (MCID) in CLBP based on previously reported findings. ${ }^{58}$ Twice as many participants reported being a responder ( $\geq 2$ decrease in pain scale) in 

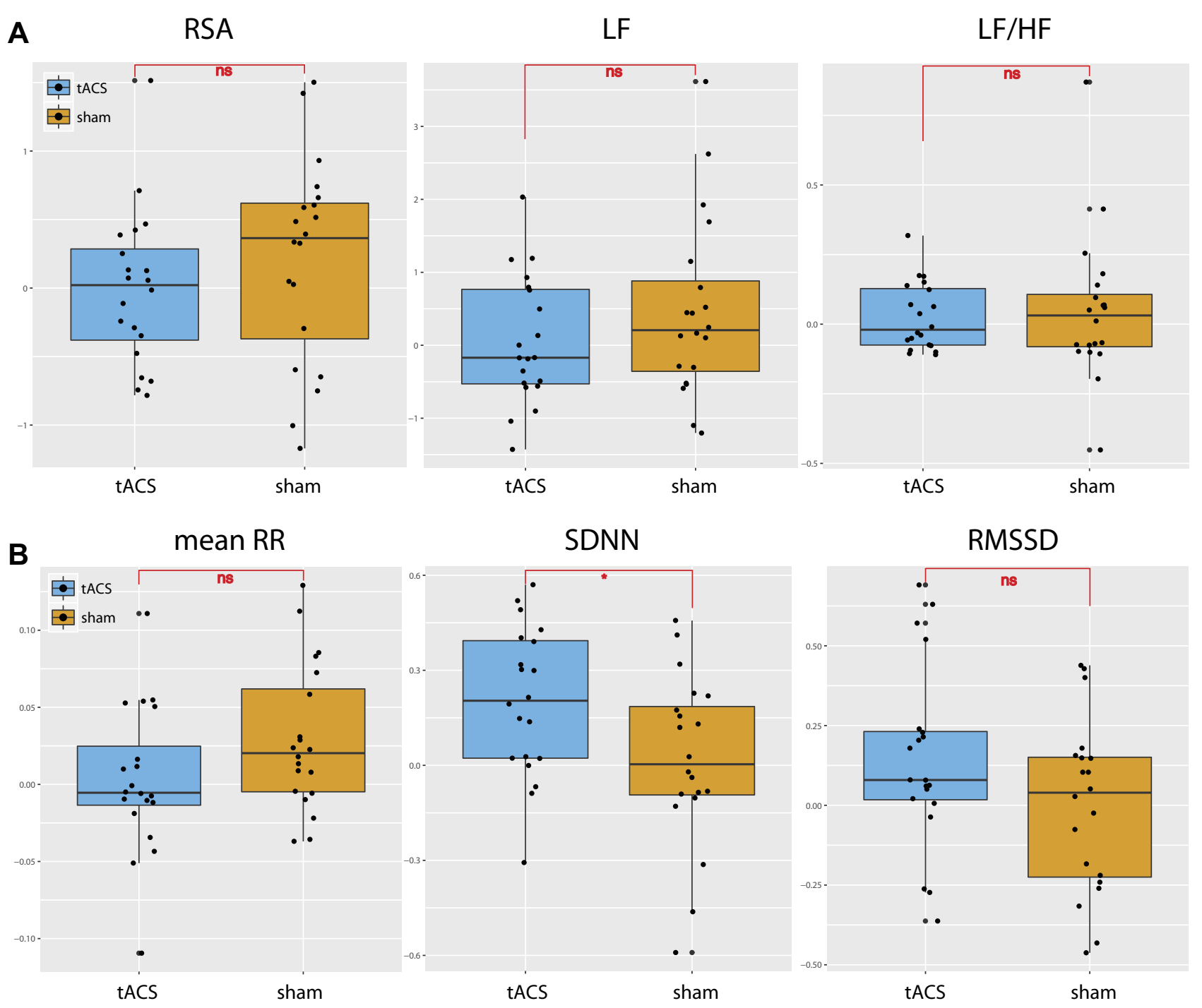

Figure 3 HRV changes [ $\ln ($ post)-In(pre)] between tACS and sham conditions for (A) frequency-domain HRV components; RSA, LF, and LF/HF and for (B) time-domain HRV components; mean RR, SDNN, and RMSSD. ( ${ }^{\mathrm{p}}<0.05$, ns: not significant).

the 10Hz-tACS versus the sham condition ( 8 of responders in 10Hz-tACS vs 4 of responders in sham). A chi-square test of independence was performed to examine the relation between stimulation condition and classification as responder. The relation between these variables did not reach statistical significance, $\chi^{2}(2, \mathrm{~N}=2)=14.14$, $p=0.15$, with a high odds Ratio $(\mathrm{OR}=2.67)$.

\section{Blinding and Side Effects}

Participants were asked how sure they were of having received stimulation on a visual analog scale (0-100). A $t$-test was used to analyze confidence in stimulation. There was no significant difference between conditions ( $t(36.74)$ $=1.38, \mathrm{p}=0.18$ ), therefore blinding was considered successful. All participants completed a side-effect questionnaire after both sessions and there were no significant differences in any of the queried potential side-effects between active $10 \mathrm{~Hz}$ and sham conditions (Table 4).

\section{Discussion}

In this study, we investigated how non-invasive brain stimulation (10Hz-tACS) alters ANS balance measured with RSA and how these metrics correlated with the level of pain and other self-report characteristics. Contrary to our hypothesis, we found that there was no effect of 10Hz-tACS on RSA. Previous studies using transcranial direct current stimulation increased RSA in healthy participants. ${ }^{59,60}$ However, we found a significant increase in SDNN for $10 \mathrm{~Hz}$-tACS relative to sham. Our exploratory analyses to find a relationship between baseline RSA and pain severity did not show any 
Table 2 Pre and Post Stimulation Metrics Between Treatment Groups for Primary Pain and All HRV Outcome Variables

\begin{tabular}{|c|c|c|c|}
\hline Variable & $\begin{array}{l}\text { Time } \\
\text { Point }\end{array}$ & Treatment & Mean (SD) \\
\hline \multirow{6}{*}{$\begin{array}{l}\text { DVPRS (self-report } \\
\text { pain) }\end{array}$} & \multirow[t]{4}{*}{ Pre } & $10 \mathrm{~Hz}-\mathrm{tACS}$ & $4.20(1.36)$ \\
\hline & & Sham tACS & $3.95(1.35)$ \\
\hline & & $10 \mathrm{~Hz}-\mathrm{tACS}$ & $3.10(1.45)$ \\
\hline & & Sham tACS & $3.45(1.77)$ \\
\hline & \multirow{2}{*}{$\begin{array}{l}2 \text { day } \\
\text { follow-up }\end{array}$} & $10 \mathrm{~Hz}-\mathrm{tACS} \#$ & $3.37(1.26)$ \\
\hline & & Sham tACS ${ }^{+}$ & $3.24(1.31)$ \\
\hline \multirow{4}{*}{$\begin{array}{l}\text { Respiratory Sinus } \\
\text { Arrhythmia (RSA) } \\
\text { or High Frequency } \\
\text { (HF) }\end{array}$} & \multirow[t]{2}{*}{ Pre } & $10 \mathrm{~Hz}-\mathrm{tACS}$ & $5.99(1.35)$ \\
\hline & & Sham tACS & $5.12(1.75)$ \\
\hline & \multirow[t]{2}{*}{ Post } & $10 \mathrm{~Hz}-\mathrm{tACS}$ & $5.98(1.04)$ \\
\hline & & Sham tACS & $5.32(1.61)$ \\
\hline \multirow[t]{4}{*}{ Low Frequency (LF) } & \multirow[t]{2}{*}{ Pre } & $10 \mathrm{~Hz}-\mathrm{t} A C S$ & $5.15(1.56)$ \\
\hline & & Sham tACS & $4.86(1.79)$ \\
\hline & \multirow[t]{2}{*}{ Post } & $10 \mathrm{~Hz}-\mathrm{t} A C S$ & $5.21(1.08)$ \\
\hline & & Sham tACS & $5.28(1.81)$ \\
\hline \multirow[t]{4}{*}{$\mathrm{LF} / \mathrm{HF}$} & \multirow[t]{2}{*}{ Pre } & $10 \mathrm{~Hz}-\mathrm{t} A C S$ & $0.85(0.17)$ \\
\hline & & Sham tACS & $0.95(0.25)$ \\
\hline & \multirow[t]{2}{*}{ Post } & $10 \mathrm{~Hz}-\mathrm{tACS}$ & $0.87(0.12)$ \\
\hline & & Sham tACS & $1.00(0.25$ \\
\hline \multirow[t]{4}{*}{ Mean RR } & \multirow[t]{2}{*}{ Pre } & $10 \mathrm{~Hz}-\mathrm{tACS}$ & 879.54 (175.50) \\
\hline & & Sham tACS & 881.91 (126.23) \\
\hline & \multirow[t]{2}{*}{ Post } & $10 \mathrm{~Hz}-\mathrm{t} A C S$ & $851.57(174.90)$ \\
\hline & & Sham tACS & 911.18 (151.64) \\
\hline \multirow{4}{*}{$\begin{array}{l}\text { Standard Deviation } \\
\text { of RR Intervals } \\
(\mathrm{SDNN})\end{array}$} & \multirow[t]{2}{*}{ Pre } & $\mathrm{IOHz}-\mathrm{tACS}$ & $40.07(23.46)$ \\
\hline & & Sham tACS & $48.23(30.17)$ \\
\hline & \multirow[t]{2}{*}{ Post } & $10 \mathrm{~Hz}-\mathrm{tACS}$ & $48.14(27.03)$ \\
\hline & & Sham tACS & $48.55(28.38)$ \\
\hline \multirow{4}{*}{$\begin{array}{l}\text { Root Mean Square } \\
\text { of Successive } \\
\text { Differences } \\
\text { (RMSSD) }\end{array}$} & \multirow[t]{2}{*}{ Pre } & $10 \mathrm{~Hz}-\mathrm{tACS}$ & $34.56(28.29)$ \\
\hline & & Sham tACS & $42.08(36.31)$ \\
\hline & \multirow[t]{2}{*}{ Post } & $10 \mathrm{~Hz}-\mathrm{tACS}$ & $39.79(34.54)$ \\
\hline & & Sham tACS & $42.87(37.88)$ \\
\hline
\end{tabular}

Notes: Each group: $\mathrm{N}=20$ unless otherwise noted. ${ }^{*} \mathrm{n}=19,{ }^{+} \mathrm{n}=17$.

significant correlations in agreement with previous findings that included no intervention. ${ }^{61}$
Table 3 Correlations of HRV Measures (RSA and SDNN) with Pain Measures

\begin{tabular}{|l|l|l|l|l|}
\hline \multirow{2}{*}{ (A) } \\
\hline \multirow{2}{*}{ Changes (Post-Pre) } & \multicolumn{3}{l}{ RSA } & \multicolumn{2}{l|}{ SDNN } \\
\cline { 2 - 5 } & Pearson & P-value & Pearson & P-value \\
\hline DVPRS & 0.080 & 0.643 & -0.247 & 0.125 \\
ODI & 0.060 & 0.712 & -0.060 & 0.737 \\
Brachioradialis PPT(Ib) & 0.102 & 0.530 & 0.224 & 0.164 \\
Sacroiliac Joint PPT(Ib) & -0.058 & 0.720 & -0.230 & 0.153 \\
\hline (B) & \multicolumn{5}{|l}{} \\
\hline Baseline & RSA & SDNN \\
\cline { 2 - 5 } & Pearson & P-value & Pearson & P-value \\
\hline DVPRS & -0.139 & 0.557 & 0.057 & 0.812 \\
ODI & 0.140 & 0.559 & -0.169 & 0.477 \\
Brachioradialis PPT(Ib) & -0.363 & 0.116 & -0.002 & 0.993 \\
Sacroiliac Joint PPT(Ib) & -0.132 & 0.578 & -0.127 & 0.592 \\
\hline
\end{tabular}

Notes: (A) Correlations at baseline. Baseline refers to the pre-session measures of session I. (B) Correlations for the change (post-pre stimulation) at both sessions. $\mathrm{N}=20$ participants. All Pearson Correlations, all p-values $>0.10$.

Abbreviations: RSA, Respiratory Sinus Arrhythmia; SDNN, Standard Deviation of NN intervals; DVPRS, Defense and Veterans Pain Rating Scale, PPT, Pressure Pain Threshold, ODI, Oswestry Disability Index.

While both sequences had a similar tACS effect on RSA (Figure 2A, left panel), we found a trending effect of greater RSA in the tACS condition compared to sham before the intervention at both sessions (Figure 4, $F_{1,36}$ $=3.105, \mathrm{p}=0.08$ ). This finding may have limited the potential influence that $10 \mathrm{~Hz}$-tACS had on RSA as there was less potential for an intervention to increase RSA due to ceiling effects. ${ }^{62}$ Previous evidence suggests that there is an optimal range for RSA based on breathing rate and vagal input. ${ }^{22}$ Furthermore, most HRV intervention studies including biofeedback training with a slow controlled breathing rate or meditation ${ }^{63}$ and HRV changes are measured throughout a longer duration with daily sessions for six weeks. ${ }^{25,27,64}$ RSA adapts quickly due to both internal and external perturbations; ${ }^{23}$ therefore, a treatment to create a lasting effect needs to be consistent, such as structured resonance breathing training daily. ${ }^{63}$

Within our time-domain analysis, 10Hz-tACS had a significant effect on SDNN. The time-domain analysis reports the activity of the cardiac system, ${ }^{65}$ which may in turn broadly reflect ANS balance. ${ }^{15}$ SDNN is a commonly used parameter for the measurement of total HRV and represents the overall variability of both sympathetic and parasympathetic inputs to the heart. ${ }^{66}$ Many studies within chronic pain have found decreased SDNN within clinical 
Table 4 Side Effect Differences Between Conditions

\begin{tabular}{|c|c|c|c|}
\hline Side Effect & $\begin{array}{l}\text { I0Hz-tACS } \\
(\mathrm{N}=20)\end{array}$ & $\begin{array}{l}\text { Active Sham } \\
(\mathbf{N}=\mathbf{2 0})\end{array}$ & P-value \\
\hline Headache & $1.3(0.67)$ & $1.25(0.52)$ & 0.815 \\
\hline Neck pain & $1.25(0.50)$ & $\mathrm{I} .35(0.4 \mathrm{I})$ & 0.494 \\
\hline Scalp pain & $1.45(0.6)$ & $1.50(0.6)$ & 0.716 \\
\hline Tingling & $2.1(0.65)$ & $\mathrm{I} .85(0.76)$ & 0.204 \\
\hline Itching & $1.7(0.8 \mathrm{I})$ & $1.9(0.79)$ & 0.480 \\
\hline Ringing/Buzzing Noise & $1.00(0)$ & $1.15(0.49)$ & 0.186 \\
\hline Burning sensation & $1.42(0.60)$ & $1.35(0.59)$ & 0.716 \\
\hline Local redness & $1.00(0)$ & $\mathrm{I} .05(0.22)$ & 0.330 \\
\hline Sleepiness & $2.55(0.68)$ & $2.60(0.87)$ & 0.804 \\
\hline Trouble concentrating & $1.65(0.92)$ & $1.9(0.94)$ & 0.287 \\
\hline Improved mood & I.45 (0.69) & $1.15(0.37)$ & 0.259 \\
\hline Worsening of mood & $1.10(0.31)$ & $1.15(0.36)$ & 0.577 \\
\hline Dizziness & $1.00(0)$ & $1.05(0.22)$ & 0.330 \\
\hline Flickering lights & I.35 (0.75) & $1.15(0.49)$ & 0.428 \\
\hline
\end{tabular}

Notes: A side effects questionnaire was completed after stimulation at both sessions with $1=$ absent, 2=mild, 3=moderate, 4=severe. The Mean (SD) are reported for both conditions and paired $t$-tests were used to test for differences between groups.

populations compared to healthy controls ${ }^{15}$ and HRV suppression has been correlated with pain severity or disability perception. ${ }^{61,67,68}$ One study ${ }^{69}$ measured SDNN in patients with spinal cord injury (SCI) with and without neuropathic pain and found significant lower resting SDNN in SCI patients with pain compared to SCI without pain and healthy controls. Since SDNN includes input from both the parasympathetic and sympathetic input, few conclusions on the increase of specific ANS branches can be drawn, ${ }^{15}$ but SDNN has been hypothesized to provide objective quantification of analgesic response to pain treatment. ${ }^{69}$ Therefore, increasing overall HRV (SDNN) may be beneficial in patients with CLBP, and HRV intervention studies have shown increases in total $\mathrm{HRV}^{27}$ Our findings thus suggest

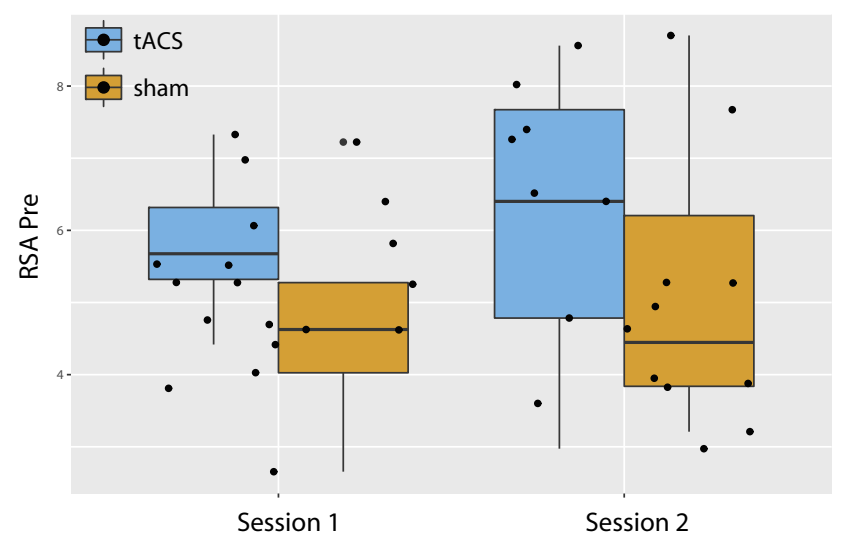

Figure 4 Baseline RSA values before stimulation (tACS and sham) in both sessions. that SDNN may be a better target than RSA, at least for a single session of $10 \mathrm{~Hz}-\mathrm{tACS}$.

We previously reported a significant stimulation effect on pain severity change (DVPRS) ${ }^{13}$ yet PPT is a measure of acute pain processing and we were not recording HRV during completion of pain metrics and PPT. While we expected individuals who had a decrease in spontaneous pain severity to have an increase in parasympathetic activation, there was no correlation between change on DVPRS and change of RSA. We included SDNN in our exploratory correlation analyses since there was a stimulation main effect. We also investigated the relationship between PPT and HRV, finding no significant correlations with either the SI joint or brachioradialis and RSA or SDNN.

As with any scientific study, the work presented here has limitations. First, this was a pilot study and thus not designed to establish statistical significance for small effect sizes. Our within-subject design increased our statistical power and is a strength considering large between-subject variation in many HRV components. ${ }^{70}$ Nevertheless, all statistical results should be interpreted cautiously given the small sample size and wide age range that may influence the physiological response. ${ }^{71} \mathrm{We}$ did find that some HRV components correlated with age (Supplementary Figure 1), yet after controlling for age our findings remained (Supplementary Table 2). Second, we did not collect medication and lifestyle information unrelated to pain, such as antihistamines or caffeine use, both of which have been shown to influence HRV, albeit the within-subjects design should reduce the impact of such external factors. ${ }^{70}$ Third, we only analyzed 2 mins of ECG data for HRV analysis following other studies in the field. ${ }^{72,73}$ However, the current gold standard for HRV recordings is at least 5 mins $^{74}$ and our study may have benefited from longer recordings. Fourth, our crossover study design only allowed for one session of active stimulation. TACS may have an additive effect on modulating oscillations if a design with multiple sessions was used. ${ }^{75,76}$

Given our findings of successful target engagement of alpha oscillations that correlated with clinical pain improvement as reported in our previous paper, ${ }^{13}$ tACS has the potential to provide a safe, scientifically supported, low-cost treatment option. However, more research utilizing tACS is needed to replicate our results and further dissect the underlying mechanism(s). Our detailed characterization (Tables 1 and 2) of the patient population provided here can be used to inform the planning of future tACS studies including the use of power calculations to inform sample size and measures collected. Future studies 
involving multiple stimulation sessions are the next steps since recurring stimulation sessions are likely needed to produce perceptible and lasting clinical effects due to presumed underlying mechanisms that appear to be related synaptic plasticity. ${ }^{77}$ Several studies have investigated non-invasive brain stimulation techniques in patients with chronic pain, but treatment effects vary across the studies, and typically only clinical outcomes are reported. We aimed to identify objective biological targets using EEG and ECG to better understand the action of $10 \mathrm{~Hz}-\mathrm{tACS}$ and the role of the ANS in chronic pain. Our results presented here along with those in our previous paper ${ }^{13}$ show that brain network dynamics and self-reported pain seem to be more sensitive ways than HRV metrics to measure the effects of brain stimulation for individuals with CLBP.

\section{Data Sharing Statement}

All deidentified raw data will be provided to the research community upon request by email to the corresponding author.

\section{Acknowledgments}

This work was supported by the National Institute of Mental Health of the National Institutes of Health under Award Numbers R01MH111889 and R01MH101547, the National Center for Advancing Translational Sciences (NCATS), National Institutes of Health, through Grant Award Number UL1TR002489. The content is solely the responsibility of the authors and does not necessarily represent the official views of the NIH. We gratefully acknowledge the help and support from the Carolina Center for Neurostimulation. We especially thank Donghyeon Kim (Neurophet Inc.,) for providing his valuable feedback on the stimulation montage and electric field modeling.

\section{Author Contributions}

F.F., J.H.P., and K.L.M designed the study. J.H.P. and M.L. A. performed the study. J.H.P., M.D, and S.A. analyzed the HRV data. J.H.P and F.F. wrote the manuscript and all authors contributed to revising the article, gave final approval of the version to be published, and agree to be accountable for all aspects of the work.

\section{Funding}

This work was supported by the National Institute of Mental Health of the National Institutes of Health under
Award Numbers R01MH111889 and R01MH101547, the National Center for Advancing Translational Sciences (NCATS), National Institutes of Health, through Grant Award Number UL1TR002489.

\section{Disclosure}

F.F. is the lead inventor of IP filed by UNC. The clinical studies performed in the Frohlich Lab have received a designation as conflict of interest with administrative considerations. F.F. is the founder, CSO and majority owner of Pulvinar Neuro LLC, a company that markets research tDCS and tACS devices for research only. Pulvinar Neuro played no role in the study reported here. F.F. has received research funding from the National Institute of Health, the Brain Behavior Foundation, the Foundation of Hope, the Human Frontier Science Program, Tal Medical, NeuroCare Group, and individual donations. F.F. is an adjunct professor in Neurology at the Insel Hospital of the University of Bern, Switzerland. F.F. receives royalties for his textbook Network Neuroscience published by Academic Press. The authors report no other conflicts of interest in this work.

\section{References}

1. Baliki MN, Apkarian AV. Nociception, pain, negative moods, and behavior selection. Neuron. 2015;87(3):474-491. doi:10.1016/j. neuron.2015.06.005

2. Ferrari R, Zanolin ME, Duse G, Visentin M. Effectiveness of opioid analgesics in chronic noncancer pain. Pain Pract. 2015;15 (3):272-278. doi:10.1111/papr.12176

3. Dowell D, Haegerich TM, Chou R. CDC guideline for prescribing opioids for chronic pain-United States, 2016. JAMA. 2016;315 (15):1624-1645. doi:10.1001/jama.2016.1464

4. Chou R, Turner JA, Devine EB, et al. The effectiveness and risks of long-term opioid therapy for chronic pain: a systematic review for a National Institutes of Health Pathways to Prevention Workshop. Ann Intern Med. 2015;162(4):276-286. doi:10.7326/M14-2559

5. Freburger JK, Carey TS, Holmes GM. Physical therapy for chronic low back pain in North Carolina: overuse, underuse, or misuse? Phys Ther. 2011;91(4):484-495. doi:10.2522/ptj.20100281

6. Pengel LHM, Herbert RD, Maher CG, Refshauge KM. Acute low back pain: systematic review of its prognosis. BMJ. 2003;327 (7410):323. doi:10.1136/bmj.327.7410.323

7. Luedtke K, Rushton A, Wright C, et al. Effectiveness of transcranial direct current stimulation preceding cognitive behavioural management for chronic low back pain: sham controlled double blinded randomised controlled trial. BMJ. 2015;16(350):h1640. doi:10.1136/ bmj.h1640

8. Ploner M, Sorg C, Gross J. Brain rhythms of pain. Trends Cogn Sci (Regul Ed). 2017;21(2):100-110. doi:10.1016/j.tics.2016.12.001

9. Lee YC, Nassikas NJ, Clauw DJ. The role of the central nervous system in the generation and maintenance of chronic pain in rheumatoid arthritis, osteoarthritis and fibromyalgia. Arthritis Res Ther. 2011;13(2):211. doi:10.1186/ar3306

10. Nir -R-R, Sinai A, Moont R, Harari E, Yarnitsky D. Tonic pain and continuous EEG: prediction of subjective pain perception by alpha-1 power during stimulation and at rest. Clin Neurophysiol. 2012;123 (3):605-612. doi:10.1016/j.clinph.2011.08.006 
11. Ploner M, Gross J, Timmermann L, Pollok B, Schnitzler A. Pain suppresses spontaneous brain rhythms. Cereb Cortex. 2006;16 (4):537-540. doi:10.1093/cercor/bhj001

12. O'Connell NE, Marston L, Spencer S, DeSouza LH, Wand BM. Noninvasive brain stimulation techniques for chronic pain. Cochrane Database Syst Rev. 2018;16(3):CD008208.

13. Ahn S, Prim JH, Alexander ML, McCulloch KL, Fröhlich F. Identifying and engaging neuronal oscillations by transcranial alternating current stimulation in patients with chronic low back pain: a randomized, crossover, double-blind, sham-controlled pilot study. J Pain. 2018.

14. Södervall J, Karppinen J, Puolitaival J, et al. Heart rate variability in sciatica patients referred to spine surgery: a case control study. BMC Musculoskelet Disord. 2013;26(14):149. doi:10.1186/1471-2474-14-149

15. Tracy LM, Ioannou L, Baker KS, Gibson SJ, Georgiou-Karistianis N, Giummarra MJ. Meta-analytic evidence for decreased heart rate variability in chronic pain implicating parasympathetic nervous system dysregulation. Pain. 2016;157(1):7-29. doi:10.1097/j.pain.00000 00000000360

16. Denver JW, Reed SF, Porges SW. Methodological issues in the quantification of respiratory sinus arrhythmia. Biol Psychol. 2007;74(2):286-294. doi:10.1016/j.biopsycho.2005.09.005

17. Porges SW. A phylogenetic journey through the vague and ambiguous Xth cranial nerve: a commentary on contemporary heart rate variability research. Biol Psychol. 2007;74(2):301-307. doi:10.1016/ j.biopsycho.2006.08.007

18. Reyes Del Paso GA, Langewitz W, Mulder LJM, van Roon A, Duschek S. The utility of low frequency heart rate variability as an index of sympathetic cardiac tone: a review with emphasis on a reanalysis of previous studies. Psychophysiology. 2013;50(5):477-487. doi:10.1111/psyp.12027

19. Mathias CJ, Bannister SR, editors. Autonomic Failure: A Textbook of Clinical Disorders of the Autonomic Nervous System. Vol. 5. illustrated. OUP Oxford; 2013.

20. Nazarewicz J, Verdejo-Garcia A, Giummarra MJ. Sympathetic pain? A role of poor parasympathetic nervous system engagement in vicarious pain states. Psychophysiology. 2015;52(11):1529-1537. doi: $10.1111 /$ psyp. 12516

21. Porges SW. The polyvagal theory: phylogenetic substrates of a social nervous system. Int $J$ Psychophysiol. 2001;42(2):123-146. doi:10.1016/S0167-8760(01)00162-3

22. Porges SW. The polyvagal theory: new insights into adaptive reactions of the autonomic nervous system. Cleve Clin J Med. 2009;76 (Suppl 2):S86-90. doi:10.3949/ccjm.76.s2.17

23. Kolacz J, Porges SW. Chronic diffuse pain and functional gastrointestinal disorders after traumatic stress: pathophysiology through a polyvagal perspective. Front Med (Lausanne). 2018;31(5):145. doi:10.3389/fmed.2018.00145

24. Berry ME, Chapple IT, Ginsberg JP, Gleichauf KJ, Meyer JA, Nagpal ML. Non-pharmacological intervention for chronic pain in veterans: a pilot study of heart rate variability biofeedback. Glob Adv Health Med. 2014;Mar(2):28-33. doi:10.7453/gahmj.2013.075

25. Hassett AL, Radvanski DC, Vaschillo EG, et al. A pilot study of the efficacy of heart rate variability (HRV) biofeedback in patients with fibromyalgia. Appl Psychophysiol Biofeedback. 2007;32(1):1-10. doi:10.1007/s10484-006-9028-0

26. Hoffman BM, Papas RK, Chatkoff DK, Kerns RD. Meta-analysis of psychological interventions for chronic low back pain. Health Psychol. 2007;26(1):1-9. doi:10.1037/0278-6133.26.1.1

27. Hallman DM, Olsson EMG, von Schéele B, Melin L, Lyskov E. Effects of heart rate variability biofeedback in subjects with stress-related chronic neck pain: a pilot study. Appl Psychophysiol Biofeedback. 2011;36(2):71-80. doi:10.1007/s10484-011-9147-0

28. Helfrich RF, Schneider TR, Rach S, Trautmann-Lengsfeld SA, Engel AK, Herrmann CS. Entrainment of brain oscillations by transcranial alternating current stimulation. Curr Biol. 2014;24(3):333-339. doi:10.1016/j.cub.2013.12.041
29. Fröhlich F, Sellers KK, Cordle AL. Targeting the neurophysiology of cognitive systems with transcranial alternating current stimulation. Expert Rev Neurother. 2015;15(2):145-167. doi:10.1586/14737175.2015.99 2782

30. Fröhlich F. Endogenous and exogenous electric fields as modifiers of brain activity: rational design of noninvasive brain stimulation with transcranial alternating current stimulation. Dialogues Clin Neurosci. 2014;16(1):93-102.

31. Ahamed S, Sheriff R. Analysis of heart rate variability in patients with chronic rheumatoid arthritis. Int J Clin Exp Physiol. 2016;3 (4):204. doi:10.4103/2348-8832.196914

32. Evrengül H, Dursunoglu D, Cobankara V, et al. Heart rate variability in patients with rheumatoid arthritis. Rheumatol Int. 2004;24 (4):198-202. doi:10.1007/s00296-003-0357-5

33. Appelhans BM, Luecken LJ. Heart rate variability as an index of regulated emotional responding. Rev Gen Psychol. 2006;10 (3):229-240. doi:10.1037/1089-2680.10.3.229

34. Sanya EO, Brown CM, Wilmowsky C. Impairment of Parasympathetic Baroreflex Responses in Migraine Patients. Acta neurologica ...; 2005.

35. Kulshreshtha P, Gupta R, Yadav RK, Bijlani RL, Deepak KK. A comprehensive study of autonomic dysfunction in the fibromyalgia patients. Clin Auton Res. 2012;22(3):117-122. doi:10.1007/s10286011-0150-6

36. Meeus M, Goubert D, De Backer F, et al. Heart rate variability in patients with fibromyalgia and patients with chronic fatigue syndrome: a systematic review. Semin Arthritis Rheum. 2013;43 (2):279-287. doi:10.1016/j.semarthrit.2013.03.004

37. Zimmerman M, Martinez JH, Young D, Chelminski I, Dalrymple K. Severity classification on the hamilton depression rating scale. $J$ Affect Disord. 2013;150(2):384-388. doi:10.1016/j.jad.2013.04.028

38. Spielberger CD, Gorsuch RL, Lushene RE, Vagg PR. State-trait anxiety inventory (STAI). BiB. 2010.

39. Carver CS, White TL. Behavioral inhibition, behavioral activation, and affective responses to impending reward and punishment: the BIS/BAS scales. J Pers Soc Psychol. 1994;67(2):319-333. doi:10.1037/00223514.67.2.319

40. Jorm AF, Christensen H, Henderson AS, Jacomb PA, Korten AE, Rodgers B. Using the BIS/BAS scales to measure behavioural inhibition and behavioural activation: factor structure, validity and norms in a large community sample. Pers Individ Dif. 1998;26(1):49-58. doi:10.1016/S0191-8869(98)00143-3

41. Sullivan MJL, Bishop SR, Pivik J. The pain catastrophizing scale: development and validation. Psychol Assess. 1995;7(4):524-532. doi:10.1037/1040-3590.7.4.524

42. Osman A, Barrios FX, Gutierrez PM, Kopper BA, Merrifield T, Grittmann L. The pain catastrophizing scale: further psychometric evaluation with adult samples. J Behav Med. 2000;23(4):351-365. doi:10.1023/A:1005548801037

43. Lovibond PF, Lovibond SH. The structure of negative emotional states: comparison of the Depression Anxiety Stress Scales (DASS) with the beck depression and anxiety inventories. Behav Res Ther. 1995;33(3):335-343. doi:10.1016/0005-7967(94)00075-U

44. Saleh KJ, Mulhall KJ, Bershadsky B, et al. Development and validation of a lower-extremity activity scale. Use for patients treated with revision total knee arthroplasty. J Bone Joint Surg Am. 2005;87 (9):1985-1994. doi:10.2106/00004623-200509000-00011

45. Nicholas MK. The pain self-efficacy questionnaire: taking pain into account. Eur J Pain. 2007;11(2):153-163. doi:10.1016/j. ejpain.2005.12.008

46. Buckenmaier CC, Galloway KT, Polomano RC, McDuffie M, Kwon N, Gallagher RM. Preliminary validation of the Defense and Veterans Pain Rating Scale (DVPRS) in a military population. Pain Med. 2013;14(1):110-123. doi:10.1111/j.1526-4637.2012.01516.x

47. Fritz JM, Irrgang JJ. A comparison of a modified oswestry low back pain disability questionnaire and the quebec back pain disability scale. Phys Ther. 2001;81(2):776-788. doi:10.1093/ptj/81.2.776 
48. Fritz CO, Morris PE, Richler JJ. Effect size estimates: current use, calculations, and interpretation. J Exp Psychol Gen. 2012;141 (1):2-18. doi:10.1037/a0024338

49. Schwarzer AC, Aprill CN, Bogduk N. The sacroiliac joint in chronic low back pain. Spine. 1995;20(1):31-37. doi:10.1097/00007632 199501000-00007

50. Farasyn A, Lassat B. Cross friction algometry (CFA): comparison of pressure pain thresholds between patients with chronic non-specific low back pain and healthy subjects. J Bodyw Mov Ther. 2016;20 (2):224-234. doi:10.1016/j.jbmt.2015.09.005

51. Fischer AA. Pressure algometry over normal muscles. Standard values, validity and reproducibility of pressure threshold. Pain. 1987;30(1):115-126. doi:10.1016/0304-3959(87)90089-3

52. Lewis GF, Furman SA, McCool MF, Porges SW. Statistical strategies to quantify respiratory sinus arrhythmia: are commonly used metrics equivalent? Biol Psychol. 2012;89(2):349-364. doi:10.1016/j. biopsycho.2011.11.009

53. Davila MI. Noncontact Extraction Of Human Arterial Pulse With A Commercial Digital Color Video Camera. Chicago: University of Illinois at Chicago (2012). Ph.D. thesis.

54. Shaffer F, Ginsberg JP. An overview of heart rate variability metrics and norms. Front Public Health. 2017;28(5):258. doi:10.3389/ fpubh.2017.00258

55. Porges SW 4,510,944. Washington, DC: US Patent and Trademark Office.

56. Porges SW, Bohrer RE, The Analysis of Periodic Processes in Psychophysiological Research. Principles of Psychophysiology: Physical, Social, and Inferential Elements [Internet]. New York, NY: Cambridge University Press; 1990:708-753. [cited September 22, 2018]. Available from: http://psycnet.apa.org/record/1990-98757-021.

57. Davila MI, Lewis GF, Porges SW. The PhysioCam: A Novel NonContact Sensor to Measure Heart Rate Variability in Clinical and Field Applications. Front Public Health. 2017;5:300. doi:10.3389/ fpubh.2017.00300

58. Katz NP, Paillard FC, Ekman E. Determining the clinical importance of treatment benefits for interventions for painful orthopedic conditions. J Orthop Surg Res. 2015;3(10):24. doi:10.1186/s13018014-0144-X

59. Nikolin S, Boonstra TW, Loo CK, Martin D. Combined effect of prefrontal transcranial direct current stimulation and a working memory task on heart rate variability. PLoS One. 2017;12(8):e0181833. doi:10.1371/journal.pone.0181833

60. Montenegro RA, Farinatti PDTV, Fontes EB, et al. Transcranial direct current stimulation influences the cardiac autonomic nervous control. Neurosci Lett. 2011;497(1):32-36. doi:10.1016/j. neulet.2011.04.019

61. Gockel M, Lindholm H, Niemistö L, Hurri H. Perceived disability but not pain is connected with autonomic nervous function among patients with chronic low back pain. J Rehabil Med. 2008;40 (5):355-358. doi:10.2340/16501977-0172

62. Reynard A, Gevirtz R, Berlow R, Brown M, Boutelle K. Heart rate variability as a marker of self-regulation. Appl Psychophysiol Biofeedback. 2011;36(3):209-215. doi:10.1007/s10484-011-9162-1
63. Lehrer PM, Gevirtz R. Heart rate variability biofeedback: how and why does it work? Front Psychol. 2014;21(5):756.

64. Sielski R, Rief W, Glombiewski JA. Efficacy of biofeedback in chronic back pain: a meta-analysis. Int J Behav Med. 2017;24 (1):25-41. doi:10.1007/s12529-016-9572-9

65. Wang H-M, Huang S-C. SDNN/RMSSD as a surrogate for LF/HF: a revised investigation. Modell Simul Eng. 2012;2012:1-8. doi:10.1155/2012/931943

66. Wulsin L, Herman J, Thayer JF. Stress, autonomic imbalance, and the prediction of metabolic risk: a model and a proposal for research. Neurosci Biobehav Rev. 2018;86:12-20. doi:10.1016/j.neubiorev. 2017.12.010

67. Hallman DM, Ekman AH, Lyskov E. Changes in physical activity and heart rate variability in chronic neck-shoulder pain: monitoring during work and leisure time. Int Arch Occup Environ Health. 2014;87(7):735-744. doi:10.1007/s00420-013-0917-2

68. Mostoufi SM, Afari N, Ahumada SM, Reis V, Wetherell JL. Health and distress predictors of heart rate variability in fibromyalgia and other forms of chronic pain. J Psychosom Res. 2012;72(1):39-44. doi:10.1016/j.jpsychores.2011.05.007

69. Karri J, Zhang L, Li S, Chen Y-T, Stampas A, Li S. Heart rate variability: a novel modality for diagnosing neuropathic pain after spinal cord injury. Front Physiol. 2017;18(8):495. doi:10.3389/ fphys.2017.00495

70. Quintana DS, Heathers JAJ. Considerations in the assessment of heart rate variability in biobehavioral research. Front Psychol. 2014;22(5):805.

71. Byrne EA, Fleg JL, Vaitkevicius PV, Wright J, Porges SW. Role of aerobic capacity and body mass index in the age-associated decline in heart rate variability. $J$ Appl Physiol. 1996;81(2):743-750. doi:10.1152/jappl.1996.81.2.743

72. Dekker JM, Crow RS, Folsom AR, et al. Low heart rate variability in a 2-minute rhythm strip predicts risk of coronary heart disease and mortality from several causes: the ARIC study. Atherosclerosis risk in communities. Circulation. 2000;102(11):1239-1244. doi:10.1161/ 01.CIR.102.11.1239

73. Shankar N, Thakur M, Tandon OP, Saxena AK. Autonomic Status and Pain Profile in Patients of Chronic Low Back Pain and Following Electro Acupuncture Therapy: A Randomized Control Trial. Indian J Physiol ...; 2011.

74. Malik M. Heart Rate Variability. Ann Noninv Electrocard. 1996;1 (2):151-181. doi:10.1111/anec.1996.1.issue-2

75. Mellin JM, Alagapan S, Lustenberger C, et al. Randomized trial of transcranial alternating current stimulation for treatment of auditory hallucinations in schizophrenia. Eur Psychiatry. 2018;51:25-33. doi:10.1016/j.eurpsy.2018.01.004

76. Ahn S, Mellin JM, Alagapan S, et al. Targeting reduced neural oscillations in patients with schizophrenia by transcranial alternating current stimulation. Neuroimage. 2018;24(186):126-136.

77. Ziemann U, Ilić TV, Pauli C, Meintzschel F, Ruge D. Learning modifies subsequent induction of long-term potentiation-like and long-term depression-like plasticity in human motor cortex. J Neurosci. 2004;24 (7):1666-1672. doi:10.1523/JNEUROSCI.5016-03.2004
Journal of Pain Research

\section{Publish your work in this journal}

The Journal of Pain Research is an international, peer reviewed, open access, online journal that welcomes laboratory and clinical findings in the fields of pain research and the prevention and management of pain. Original research, reviews, symposium reports, hypothesis formation and commentaries are all considered for publication. The manuscript

Submit your manuscript here: https://www.dovepress.com/journal-of-pain-research-journal management system is completely online and includes a very quick and fair peer-review system, which is all easy to use. Visit http:// www.dovepress.com/testimonials.php to read real quotes from published authors. 